\title{
О КОНЦЕПТУАЛЬНО-ТЕОРЕТИЧЕСКИХ ПОДХОДАХ К ИССЛЕДОВАНИЮ ОСОБЕННОСТЕЙ ПРОЯВЛЕНИЯ «ГЛОБАЛЬНОЕ - ЛОКАЛЬНОЕ» В МИРОВОЙ ЭКОНОМИКЕ
}

\author{
(c) 2020 Бянь Цзыцзин \\ аспирантка кафедры экономической теории и менеджмента \\ Московский педагогический государственный университет, Россия, Москва \\ E-mail: Chairt.etm@bk.ru \\ ( 2020 Платонова Елена Дмитриевна \\ доктор экономических наук, профессор, \\ заведующий кафедрой экономической теории и менеджмента \\ Московский педагогический государственный университет, Россия, Москва \\ E-mail: ed.platonova@mpgu.edu
}

В конце второй декады XX века в системе международных экономических отношениях происходят качественные сдвиги, которые теоретически должны быть осмыслены в концепциях, адекватно отражающих новое соотношение глобального и локального в мировой экономике. В статье проанализированы концептуально-теоретические подходы к исследованию особенностей проявления «глобальное - локальное» в мировой экономике, а также рассмотрены концепции трансформизма, гиперглобализма, скептицизма, «нового» глобализма и «нового» регионализма. Авторы приходят к выводу о том, что новое соотношение «глобальное - локальное» в мировой экономике должно отражено в теоретической концепции влияния закономерностей глобализации на создание и развитие региональных экономических интеграционных объединений.

Ключевые слова: мировая экономика, глобализация, гиперглобализм, регионализм, региональные экономические интеграционные объединения, трансформизм, скептицизм.

В настоящее время мировая экономика ощущает воздействие новых факторов своего развития, когда уже изученные черты экономической глобализации не в полной мере отражают ее современное состояние. Закономерности глобализации проявляются в модифицированном виде, а их характеристика отличается от устоявшихся классических определений глобальных процессов. В этой связи необходимо обратиться к теоретико-концептуальным подходам к исследованию особенностей проявления закономерностей глобализации мировой экономики с тем, чтобы обобщить имеющиеся определения и выявить новые элементы современного этапа движения «мир-экономики», понятой в широком смысле.

В условиях новой экономики, обстоятельный анализ содержания которой был дан зарубежными и российским российскими исследователями (Дж. Бхагвати, П.Кругман, Р. Робертсон, Е.Ф.Авдокушин, Е. Винокуров, Б.Хейфиц и др.), ускоряется не только смена технико-технологических основ общественного производства, но и процесс взаимной адаптации и асимметрическо-

го взаимодействия глобальных и глокальных процессов. На глобализационные тенденции, преобладавшие со середины 80-х годов прошлого века, накладывается региональная специфика, обусловленная созданием региональных экономических группировок (РЭГ) по линии «North-South» и «South-South», стран-участники которых стремятся ослабить негативные эффекты жесткой международной конкуренции и создать условия развития для национальногосударственных систем в рамках РЭГ. Действительно по данным ВТО наблюдается рост региональных торговых соглашений, составляющих экономическую основу региональных образований: в 2019 г.- 301 соглашение; в 2009 г. -201 соглашение, а в 1999 г. - 72 соглашения[12].

В теоретической проекции данные процессы нашли свое отражение в многочисленных концепциях, рассматривающих взаимоотношение «глобальное -локальное», в том числе, в аспекте соотношения «региональная интеграция - глокальность». Об усилении роли данных процессов свидетельствует не столько появление нового термина «глокальность», в котором нашло 
органическое сочетание свойств «глобальности» («global») и «локальности» («localization»), сколько его достаточно широкое распространение[10].

Среди концепций, в которых отражена специфика сочетания «глобальное - локальное», остановимся на теоретических построениях исследователей, обобщенных в таких концепциях, как трансформизм, гиперглобализм, скептицизм, «новый» глобализм и «новый» регионализм.

Основные положения концепции трансформизма сформулированы достаточно многочисленной группой исследователей, среди которых особо выделим вклад Р. Робертсона, М. Фезерстоуна, С.Леша и других представителей социологического направления [11, с.89-92; 7].

Глобализация трактуется как основная закономерность развития современного мира, которая отражает радикальные трансформации во всех сферах человеческого общества. Анализируя парадигму глобализации, Мухаммад Айиш замечает, что эмпирический анализ процессов глобализации состоит из четырех компонентов: политического; экономического; культурного и технологического. При этом, по мнению автора, имеет место активное взаимодействие локальных и глобальных тенденций в политических, культурных, экономических и технологических сферах с преобладанием глокализационных процессов [13]. Несмотря на то, что объект исследований социологов - глобализация в широком смысле, выводы из социологических исследований имеют экономическое преломление: экономическая глокализация - это локальная реакция основных экономических субъектов национально-государственных систем на интенсификацию глобальных процессов, а, именно, на открытие иностранному капитала национальных рынков сбыта и источников ресурсов, усиление трансграничных потоков товаров, формирование трансграничных производственных и коммуникационных систем. В этих условиях не все локальные экономические субъекты «вписались» в эти глобализационные тренды, поэтому реакция на данные тренды - сформировать локальные экономические «локуны» путем создания РЭГ и трансформировать «глобальное» в «локальное».

Интересна в связи с рассматриваемой концепцией трансформации позиция известного исследователя транснациональных корпораций Глации Йетто-Джиллис, которая анализирует особенности мировой торговли и акцентирует внимание: во-первых, на новой геопространственной конфигурации - «глокализации» - как комбинации факторов в мировой хозяйственной системе в процессе адаптации глобальных товаров к локальным рынкам; во-вторых, на адаптацию и трансформацию глобальных производственных процессов к имеющимся в определенных странах производственным ресурсам; в-третьих, на локализацию составляющих производства факторов по принципам локализации профессии, навыков и профессионального мастерства; в-четвертых, на тактике ТНК на локализацию производств и трансформацию производственных процессов от материнской компании к дочерним, которые локализуются на местных рынках [14]. В данной трансформации заложены противоречия, поскольку, как отмечает немецкий исследователь Ульрих Бек, если государства придерживаются «постулата о суверенитете национальной политики, то усиливается конкурентная борьба между государствами за инвестиции и привязанность государства к одной национальности становится преградой для транснационального развития политики» [3, c.130]. В этом случае неизбежна трансформация межгосударственных экономических процессов во внутриглобальные (глокальные).

На протяжении значительного времени в научной и справочной англоязычной литературе была широко распространена концепция гиперглобализма, представленная видными ее представителями Э.Бжезинским, К. Омае, Милтон Фридман и другие $[2,5]$. Данная концепция, которая также известна как «революционный» глобализм, основана на абсолютизации неолиберальной глобализации и западных ценностей. Глобализм олицетворяет новую эпоху развития человечества, содержание которой в становлении развитии единого глобального мирового хозяйства, а развитие национально-государственных экономических систем вне его - признаком отсталости. Вместе с тем, представители данного концептуального подхода не отрицают связь глобальных экономических процессов с предшествующим развитием западных экономических систем, основанных на свободной конкуренции и мотивациях «экономического» человека. На это указывают многие российские исследователи. Так, Б. Кагарлицкий, анализируя позиции западных экономистов в лице Дж.Петраса, пишет: «Петрас... обращает внимание на то, что и транснациональные корпорации име- 
ют прямых предшественников в лице торговых компаний ХПI-XVШ века» [8, С.25]. Российский экономист В.Кондратьев характеризует модель глобализации как модель, которая развивалась последние 200 лет [9, с. 5]. По мнению, представителей гиперглобализма возникающие процессы глокализации имеют только временный характер, и они должны быть рассмотрены не с точки зрения отстаивания национальных экономических интересов, а с позиции создания максимально комфортных локальных условий для локализации транснационального капитала и деятельности международного бизнеса. В этом аспекте глобализационные тренды должны поддерживаться, в том числе, наднациональными органами РЭГ, а национальные регулирующие органы обязаны выполнять предписания международных организаций (МВФ, МБ, ВТО и др.) и проводить политику «растворения» национальных экономических интересов в сфере глобального взаимодействия всех экономик в контурах единого мира - «целостного... по внутренней взаимосвязанности своих взаимопроникающих компонентов» [6, с. 193].

В положениях концепции скептицизма красной нитью проходит мысль о том, что построение всемирной экономической «Вавилонской башни» невозможно. Гиперглобализация в теории и на практике имела успех и определенную перспективу в результате крупнейших после Второй мировой войны геополитических и геоэкономических сдвигов: распада СССР и Варшавского блока, транзита плановой экономики в рыночную на значительном экономическом пространстве бывшего СЭВ и других драматических событий конца XX века.

В определенной степени концепция скептицизма отражает негативную реакцию национальных государств и национально-ориентированного бизнеса на гиперглобализм. Вместе с тем, данная концепция неоднородна и по отношению к восприятию ее представителей последствий интенсификации глобализационных процессов выделяются несколько версий. Наиболее радикальной и неоднородной по составу ее представителей является концепция так называемого антиглобализма, который не отрицает объективности интеграционных процессов в мировой экономике, но не приемлет либеральную и неолиберальную форму гиперглобализации, приводящей к унификации экономического пространства, разорению национального бизне- са, нивелирования национальных особенностей экономической культуры и диктату транснационального капитала. В экономической проекции антиглобалисты придерживают различных точек зрения на проблемы глокализации, но на первый план ставят развитие «локального» (частно - местничкового), нежели «глобального», которое усугубляет экологические проблемы и обеспечивает достойный уровень «золотого» миллиарда [1;8].

Несмотря на достаточно разнородные суждения представителей других вариаций концепции скептицизма (Л.Вайс, Дж. Миттелман, В.Иноземцев и др.), глобализация трактуется ими как «повышенный» уровень интернационализации, а не как новое явление, способное обеспечить рост благосостояния народов и простор для развития новых технологий.

В последние десятилетия концепция скептицизма получила практическую поддержку. Во-первых, кризис 2008 г. показал глубокие изъяны гиперглобализации, приведя не только к падению мировому ВВП, принятию западными интеллектуалами гипотезы о конце эры гиперглобализации и создании новых условий для экономической и финансовой архитектуры. Во-вторых, введение в 2014 году санкций против России и ответных санкций против стран, их поддержавших, подорвало доверие к правилам ВТО и всей системе регулирования внешнеэкономической деятельности в глобальной экономике. Взаимовыгодные международные экономические связи были нарушены, а экономические субъекты «единого мирового хозяйства» оказались перед реальной угрозой сжатия ресурсной базы и потери важных для них рынков сбыта. В-третьих, возрождение экономического протекционизма («трампетизм») показало, что при снижении экономических выгод от глобальных процессов страна, которая олицетворяла глобальный тренд, США, достаточно легко отказывается от концепции гиперглобализации в той ее части, которая ситуационно ей не выгодна и не принимает во внимание экономические интересы своих союзников по военнополитическому блоку НАТО. В-четвертых, пандемия-2020, объявленная ВОЗ весной 2020 г., показала возрастание роли национальных государств и национальных систем безопасности жизнеобеспечения населения.

Новая геоэкономическая «нормальность» нашла отражение в новой теоретической моде- 
ли глобализации, отдельные положения которой характеризуют усиление глокальных тенденций в развитии мировой экономики. Как справедливо отмечают исследователи, если в «старой» модели глобализации наблюдается «верховенство глобальной экономики над национальной политикой» и конвергенция «стран и экономик на основе экономических принципов, определяемых G7 и Бреттон-Вудскими институтами», то для «новой» модели - меньшая «конвергенция в повестке

дня крупнейших мировых экономик» и рост государственного капитализма на фоне укрепления национального суверенитета [9, с. 7].

Это свидетельствует о том, что во второй декаде 21 века отражение концептуального соотношения «глобальное - локальное» в новой модели глобализации сместилось в сторону «локальное». Однако в научно-теоретическом плане не найдено достаточно аргументов, чтобы отбрасывать концепцию глобализации и признать верным тезис о «конце» эры глобализации. Более точно определить тенденцию к отходу экономистов от положений теории гиперглобализации как неолиберального варианта глобализации. Действительно можно утверждать, что человечество вступило в новую - постглобальную - фазу своего развития, для которой все более актуальным становится лозунг: «Мыслить глобально, действовать локально». Однако «постглобальность» не означает исчезновение объективных основ глобальных трендов, но характеризует новую роль локальных факторов в развитии современных международных экономических отношений.

На исходе второй декады XXI века под воздействием совокупности геополитических и геоэкономических факторов, а также глубоких изменений в технико-технологических основах современного мирового хозяйства (Индустрия 4.0) актуализировались положения теоретической концепций с прилагательным «новый», а именно, «новый регионализм», которая была предложена Б.Хеттне и Ф. Содербаумом в 90-е года XX века. Несмотря на в целом единый объект исследования (процессы региональной интеграции), как теоретический конструкт «новый» регионализм выстроен на более широком подходе к самой дефиниции «регион» и отличается от «старого» регионализма, который включал различные теоретико-концептуальные подходы к функционированию европейских инсти- тутов международной региональной интеграции (дирижизм, федерализм, функционализм, неофункционализм, интерговернментализм) [11]. С позиции логико-генетического подхода «новый» регионализм сформировался как теоретическое осмысление регионализма под влиянием трендов глобализации конца XX в., роль которых представители «старого» регионализма закономерно не могли предвидеть в 50-70-х годах прошлого века.

В концепции «нового» регионализма глокализация, как относительно новый феномен, рассматриваются в контексте регионализации. В данной концепции соотношение «глобальное локальное» воспринимается как «глобальное - в локальном», что отражает диалектику развития современных мегарегионов и двойственный характер глокализации. Далеко не случайно Роберт Холтон используют такие понятия «макдоналдизация» (McDonaldization), «гроубализация» (growbalization), отражающие глубину проникновения глобальных трендов в региональное развитие [15].

При всей неоднозначности отдельных положений теория «нового» регионализма заложила концептуальные основания и методологические инструменты для системного изучения новых факторов и проблем регионализации современной мировой экономики. В контексте соотношения «глобальное - локальное» можно констатировать, что на уровне современной мегаэкономики под локальным надо понимать не региональное пространство в рамках национально-государственной системы, а межгосударственные РЭГ, которые выступают полноправным субъектом мировой экономики. Современную мировую экономику преждевременно рассматривать как унифицированное «единое мировое пространство» в понимании сторонников гиперглобализации. Действие центробежных сил в мировой экономической системе привели к возрастанию роли фактора регионализма и расширению социально-экономических функций межгосударственных РЭГ вообще, и с участием России и Китая, в частности. В этой связи выявляются контуры наиболее перспективных и аргументированных концептуальных подходов к разработке теоретической концепции влияния закономерностей глобализации на развитие межгосударственных РЭГ, которая должна отражать новое соотношение «глобальное - локальное» в мировой экономике. 


\section{Библиографический список}

1. Альтерглобализм: теория и практика «антиглобалистского движения». М.: Едиториал УРСС,2003. 256 с.

2. Бжезинский Зб. Великая шахматная доска (Господство Америки и его геостратегические императивы) / пер. О. Ю. Уральской. М.: Международные отношения, 1998. 256 с.

3. Бек У.Власти и её оппоненты в эпоху глобализма. Новая всемирно-политическая экономия.М.: Издательский дом «Территория будущего», 2007. 464 с.- С. 130

4. Бу Тун, ПлатоноваЕ.Д.Теоретико-методологические исследования региональных интеграционных моделей экономического развития современных государств: системный подход/Экономические науки. 2019.№ 8.c.7-12.

5. Вельяминов Г. Россия и глобализация// Россия в глобальном мире. 2006. № 3 Май/Июнь. URL https:// globalaffairs.ru/articles/rossiya-i-globalizacziya (Дата доступа 20ю

6. Грани глобализации. Трудные вопросы современного развития. М. Альпина Паблишер.2003.592 с.

7. Дугин А.Г. Теория многополярного мира. М.: Евразийское движение, 2013. 532 с.

8. Кагарлицкий Б. Ю. Политология революции. М.: Алгоритм. 2007. 576 с.

9. ондратьев В. Новый этап глобализации: особенности и перспективы// Мировая экономика и международные отношения. 2018, том 62. № 6, с. 5-17

10. Платонова Е.Д., Ли Тяньци. Закономерности современной глобализации: этап глокализации? // Пространственная экономика: проблемы региональных экономических объединений. Материалы XVII Mеждународной научной конференции, Россия, Москва, 29 ноября 2019, С.155-158.

11. Платонова Е.Д., Филькевич И.А., Богомолова Ю.И., Сунь Юймэн. Теоретико-методологические аспекты исследования закономерностей глобализации/Пространственная экономика: проблемы региональных экономических объединений: Материалы XIV Международной научной конференции. 20-21 июня 2016 г. С.44-47-Москва, Россия. М: МПГУ, 2016.220 с.

12. Сунь Юймэн, ПлатоноваЕ.Д. О подходах к разработке дорожной карты развития институтов интеграции в региональных межгосударственных объединениях стран с развивающимися рынками //Экономические науки, 2019, № 12. С.69-73

13. Ayish, Muhammad I. Arab World Television in the Age of Globalisation: An Analysis of Emerging Political, Economic, Cultural and Technicological Patterns. Hamburg. Deutsches Orient-Institut, 2003, in: DAVO Nachrichten, Bd. 22, Dezember 2005. 105-106.

14. Grazia Ietto-Gillies, What Role for Multinationals in the New Theories of International Trade and Location? International Review of Applied Economics, Taylor \& Francis Journals, 2000. Vol. 14(4), pages 413-426.

15. Holton R. J. Globalization and the Nation State: 2nd Edition. 2011. Published by Palgrave Macmillan.256 p. 